\title{
Reflexões metodológicas para o estudo das práticas alimentares
}

\section{Methodological approaches on the studies of food practices}

Jean-Pierre POULAIN ${ }^{1}$

Rossana Pacheco da Costa PROENÇA ${ }^{2}$

\section{RE S U M O}

A alimentação humana, envolvendo aspectos psicológicos, fisiológicos e socioculturais, é um fenômeno de grande complexidade e, em assim sendo, o estudo das práticas alimentares tem suscitado o desenvolvimento de instrumentos e métodos no interior de várias disciplinas. Neste artigo, que apresenta a alimentação humana sob abordagem da Sociologia e da Antropologia, definem-se as diferentes dimensões do espaço social alimentar, desde o registro do consumo alimentar até os processos de diferenciação social envolvendo as formas de cozinhar, as formas de consumir e a temporalidade. Analisam-se os diferentes tipos de dados que podem ser utilizados, tomando-se o cuidado de distinguir os dados comportamentais (que podem ser obtidos tanto pela observação quanto pela declaração) dos dados de representação. Apresentam-se, em seguida, os diferentes instrumentos de coleta e as vias de entrada no fenômeno alimentar. Esses instrumentos metodológicos, construídos no interior de um quadro teórico-sociológico, são propostos aos pesquisadores da área, objetivando a construção de uma possível visão comum, que proporcione uma abordagem pluridisciplinar do fato alimentar.

Termos de indexação: sociologia da alimentação, comportamento alimentar, metodologia científica, práticas alimentares, nutrição humana, hábitos alimentares.

\section{A B S T R A C T}

Human nutrition is a very complex phenomenon as it invites at the same time the physiology, the psychology and the socio-cultural. That's also why food practice measures have caused the development of tools and

\footnotetext{
1 Socioantropólogo, Professor da Université de Toulouse Le Mirail, Toulouse, France. Coordenador do Centre d'Etude du Tourisme et des Industries de l'Accueil (CETIA) e da Cellule Recherche Ingénierie Tourisme, Hôtellerie, Alimentation (CRITHA). Membro do Centre D'Étude des Rationalités et des Savoirs UMR-CNRS No5117, axe: sociologie de la santé. Correspondência para/Correspondence to: Université de Toulouse 2, CETIA , 5 allées Antonio Machado, 31058, Cedexl, Toulouse, France. E-mail: poulain@univ-tlse2.fr

2 Departamento de Nutrição, Universidade Federal de Santa Catarina. Realizando pós-doutorado no CETIA - Université Toulouse Le Mirail, como bolsista da CAPES.E-mail: rproenca@mboxl.ufsc.br
} 
methodologies within several disciplines. This article presents the approach of sociology and anthropology. It defines first of all the different dimensions of the social food space; from the eatable order to the process of social differentiation via the culinary, the consumption forms and the temporality. It analyses in detail the data types which can be used taking care in distinguishing the behavioural data that can be obtained either by observation or by declaration from the representation data. It presents the different collect tools and the ways of entry in the food phenomenon. These methodological tools built within a sociological theoretical framing are proposed to the researchers engaged in the study of the food facts so as to walk towards a pooling likely to result on a multi-field approach.

Index terms: food sociology, food behaviour, scientific methodology, food practices, human nutrition, food habits

\section{N T R O D U ÇÃ O}

A alimentação é um objeto de extrema complexidade, suscetível de mobilizar numerosas disciplinas científicas: a Epidemiologia, a Economia, a Sociologia, a Antropologia, a Nutrição, a História, a Psicologia, as disciplinas tecnológicas, entre outras. Cada uma produz, a partir de seu ponto de vista e das suas problemáticas principais, séries de dados que permitem estudar as grandes tendências de consumo (INSEE, IBGE)(3), as ligações entre alimentação e saúde ${ }^{1,2,3}, a$ diferenciação social e cultural das práticas ${ }^{4,5,6}$, entre outras possibilidades. Destaca-se, contudo, a possibilidade de estudos pluridisciplinares, trabalhando as interações entre essas diferentes dimensões.

Este artigo tem por objetivo reproduzir o momento atual de um processo de reflexão e experiência sobre a metodologia de trabalho em Sociologia da Alimentação. Esse processo vem sendo desenvolvido no decorrer do tempo, através da planificação e execução de estudos, de publicações e das conseqüentes discussões com os pesquisadores que se propõem a trabalhar esta temática. Assim, apresenta-se um apanhado de definições, questionamentos e exemplos sobre questões metodológicas envolvidas na compreensão do fato alimentar visando, principalmente, encaminhar para a possibilidade de estudos desenvolvendo abordagens pluridisciplinares dessa questão.

Qualquer que seja a perspectiva adotada, a objetivação das práticas alimentares coloca-se como uma etapa preliminar. Essa primeira etapa, que os especialistas em ciências humanas e sociais denominam de positivação, é o suporte sobre o qual se desenvolvem as diversas análises e interpretações disciplinares e constitui uma base comum que permite empreender o diálogo entre as disciplinas.

O estudo das práticas alimentares expõe três tipos de problemas metodológicos.

O primeiro refere-se à natureza dos dados com os quais o pesquisador trabalha. Que tipo de dados coletar? O que pode demonstrar aquilo que os indivíduos fazem realmente? Aquilo que eles dizem fazer? As suas opiniões, suas atitudes, seus valores em relação à alimentação em geral ou em relação a certos produtos alimentares? Esses diferentes dados são todos interessantes e permitem a condução de análises sociológicas, mas eles não dão conta do mesmo nível da realidade do fato social alimentar. Os dados de representação dão conta do que pensa o indivíduo mas, não necessariamente, do que ele faz. Assim, não devem ser considerados como dados comportamentais. É conveniente manter-se atento ao estatuto das variáveis utilizadas, sobretudo no contexto de comparações entre enquêtes ou

3 Órgãos francês e brasileiro que trabalham com coleta e análise de dados estatísticos nacionais Institut National de la Satistique et des Etudes Economiques (INSEE) e Instituto Brasileiro de Geografia e Estatística (IBGE). 
quando se realizam estudos pluridisciplinares que cruzam variáveis biológicas e variáveis sociológicas.

O segundo problema refere-se à diversidade dos métodos de coleta de dados que não permite a obtenção de dados da mesma qualidade. Com efeito, é possível coletar dados comportamentais observando-se os comedores ${ }^{(4)}$ ou solicitando aos mesmos que descrevam ao pesquisador aquilo que eles comem. Os resultados obtidos não são exatamente os mesmos, os segundos podendo ser mais ou menos deformados por esquecimentos.Assim, eles não devem ser considerados como equivalentes.

A terceira questão diz respeito às vias de entrada no espaço social alimentar. Pode-se considerar quatro níveis: as disponibilidades de alimento na escala dos países, as aquisições de alimentos analisadas por categorias sociais, as práticas domésticas de compra, de preparação e de consumo de alimentos e, por fim, as diferentes modalidades de consumo individual. Esses níveis correspondem a focos, quer dizer, a escalas de leituras complementares do fenômeno alimentar.

DAS PRÁTICAS OBSERVADAS ÀS REPRESENTAÇÕES SOCIAIS

\section{A natureza dos dados para o estudo das práticas alimentares}

Os dados que permitem descrever e compreender o fenômeno alimentar podem se distribuir sobre um continuum indo dos mais objetivos aos mais subjetivos. Partindo do primeiro pólo, temos as práticas observadas, as práticas objetivadas pelos seus traços, as práticas reconstruídas com a ajuda de instrumentos de anamnese ou rememorização, as práticas descritas de maneira espontânea, as normas sociais expressas pelo indivíduo, as opiniões, as atitudes, os valores e as representações simbólicas.

A densidade dos fatos sociais manifestase entre dois pólos que podem aparecer como os extremos de um continuum: as práticas que correspondem aos comportamentos realmente utilizados pelos comedores e suas representações, os discursos que thes são associados e que as acompanham, as determinam ou as justificam. Entre esses dois pólos pode-se observar diferentes categorias de dados (Figura 1).

\section{As práticas observadas}

Referem-se aos comportamentos alimentares realmente utilizados por um indivíduo ou um dado grupo de indivíduos. Elas podem ser registradas por observação ou com a ajuda de técnicas audiovisuais, depois decodificadas e analisadas através da utilização de descritores. A construção desses descritores é uma fase essencial da observação pois, como a realidade é sempre extremamente rica em detalhes, torna-se importante, através de uma perspectiva teórica, organizar e ter bem claros quais os aspectos importantes desta realidade que devem ser observados, registrados e, depois, analisados. No entanto, é possível estabelecer um consenso científico sobre os dados para além de perspectivas teóricas concorrentes, a partir do qual os debates teóricos podem ser desenvolvidos. Exemplos de estudos utilizando práticas observadas sob uma perspectiva de análise quantitativa podem ser encontrados em Poulain et al. (1996)9 ${ }^{9}$, (Poulain, $2001^{10}$ e $\left.2002^{11}\right)$ e de análise qualitativa, em Desjeux (1996) ${ }^{12}$.

\footnotetext{
4 A palavra francesa mangeur representa, para a Sociologia da Alimentação atual, o homem que come, razão da utilização da palavra "comedor" em português. A utilização deste termo surgiu a partir da publicação "Le mangeur du 19éme" de Jean-Paul Aron $(1976)^{7}$. Em seminário realizado em 1998, tendo como um dos temas justamente a discussão de como designar o "mangeur" humano, definiu-se pela utilização da palavra no plural, a partir da compreensão de que somos todos múltiplos quando comemos e de que múltiplos são também os tipos de "comedores" humanos, conforme explicitado em Poulain \& Proença $(2003)^{8}$.
} 


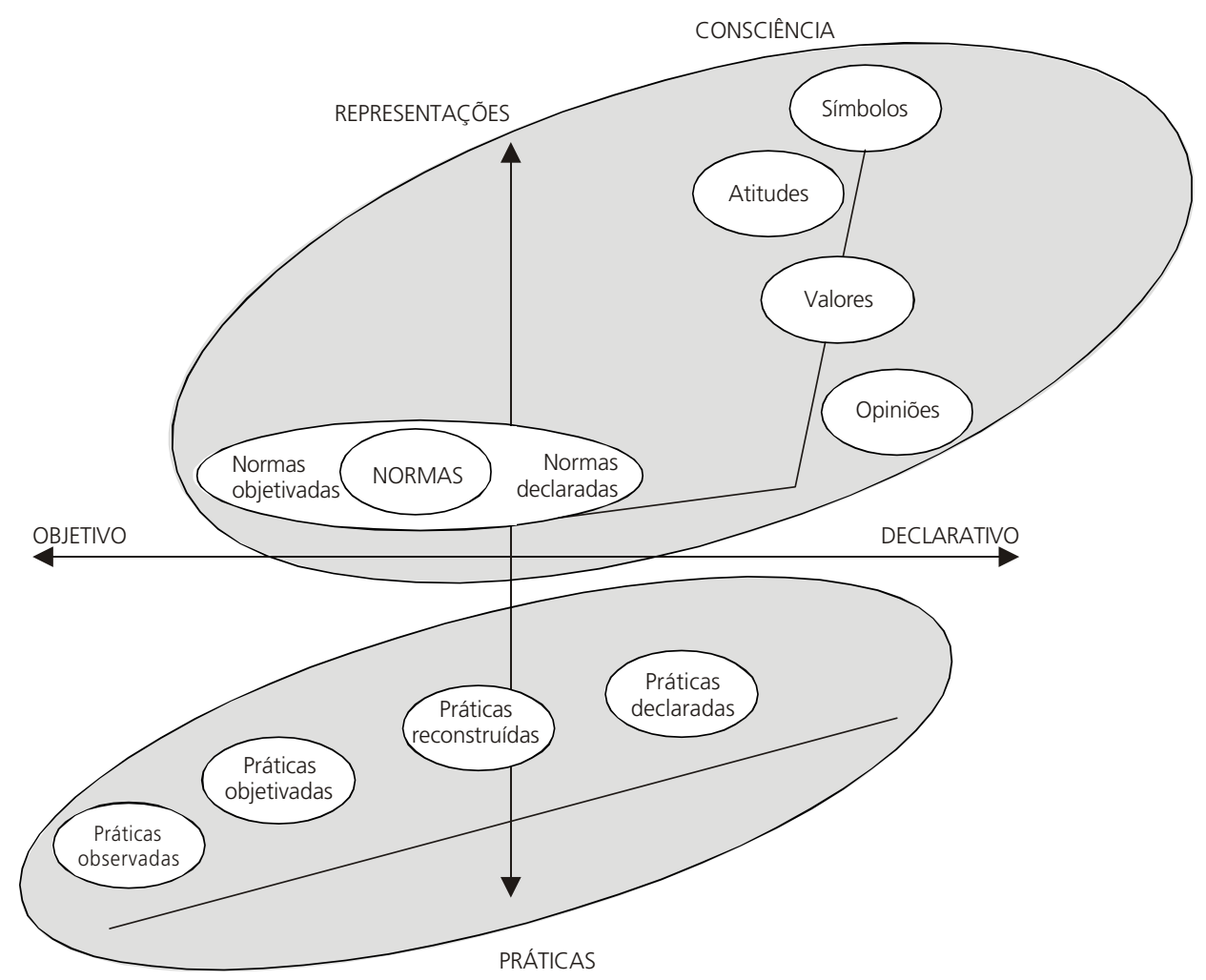

Figura 1. Os níveis do fato alimentar.

\section{As práticas objetivadas}

São os comportamentos reais, não observados diretamente, mas objetivados de maneira indireta, através dos traços que deixam. Este é o caso, por exemplo, dos fluxos econômicos, tais como disponibilidade de produtos alimentares em um país ou região, aquisições alimentares de uma dada população, bem como as vendas em determinadas lojas. Acrescentem-se, ainda, as análises de fluxos de dejetos que representam índices bastante seguros de consumo. Exemplos típicos da utilização deste tipo de dados são as análises realizadas por estudiosos de Sociologia do Consumo em dados originários dos detentores de cartões de fidelidade de lojas.

\section{As práticas reconstruídas}

São as obtidas pela solicitação, a uma determinada pessoa, de reviver, através da memória, as suas próprias práticas. O pesquisador conta com uma grade de apoio que lhe permite acompanhar a anamnese, passando sistematicamente em revista uma série de descritores previamente definidos. Esta reconstrução pode ocorrer em uma escala de tempo variada: a jornada alimentar ou as últimas 24 horas, três dias, uma semana. Ela pode interessar-se pelas freqüências de consumo solicitando ao entrevistado quantas vezes por semana ou por mês ele consome este ou aquele produto. Enfim, a reconstrução pode abordar as práticas de compra ou as práticas alimentares. As práticas reconstruídas são um instrumento metodológico bastante utilizado para análises do fato alimentar, e exemplos podem ser encontrados em Corbeau $(2002)^{13}$ ou de Assis et al. (2003) ${ }^{14}$.

\section{As práticas declaradas}

Elas correspondem àquilo que os sujeitos pretendem fazer ou já fizeram quando respondem 
de maneira espontânea a um questionamento. Essas são questões deliberadamente menos precisas do que aquelas elaboradas para a análise das práticas reconstruídas, pois o interesse recai, também, na maneira como o entrevistado vai se estruturar e se organizar no espaço de imprecisão da questão. Em relação às práticas realmente implementadas pelo indivíduo, as respostas são freqüentemente objeto de transformações, de deformações, conseqüências de fenômenos cognitivos como a reestruturação semântica, o esquecimento ou, ainda, a negação. As práticas declaradas em si mesmas, e sob a reserva de não serem consideradas como dados objetivos, apresentam o interesse de conduzir aos paradoxos que sustentam as práticas alimentares.

\section{As normas}

São representadas pelas regras, pelos modelos de conduta amplamente seguidos em uma dada sociedade ou em um dado grupo social ${ }^{15}$. Elas correspondem às práticas consideradas como "convenientes", com uma conotação moral; a não-observância de uma norma deflagra, por parte dos outros membros do grupo, sanções difusas ou explícitas ${ }^{16}$. As normas alimentares são submetidas a uma série de influências de princípios gastronômicos, culinários, dietéticos, simbólicos, etc.

Torna-se importante, no entanto, distinguir a "norma social" da "norma dietética". Essa última é constituída de um conjunto de prescrições sustentadas em conhecimentos científico-nutricionais e difundidos por profissionais da área da saúde. Modificando-se de acordo com as descobertas científicas, elas descrevem, em termos qualitativos e quantitativos, aquilo que deve ser uma alimentação suscetível de manter o ser humano em um bom estado de saúde. A "norma social", por sua vez, encaminha para um conjunto de convenções relativas à composição estrutural das tomadas alimentares(5) - durante e fora das refeições - bem como às condições e contextos do seu consumo. Neste sentido, norma social e norma dietética influenciam-se mutuamente.

Na França, a estrutura normal da refeição (norma social) é uma unidade constituída de quatro categorias: entrada, prato principal com acompanhamento, queijo e sobremesa, sendo que uma versão simplificada eliminando o queijo pode ser admitida. Já no Brasil, uma refeição completa compreende arroz, feijão, alguma preparação com carne, complemento, salada e sobremesa, sendo que as preparações salgadas são consumidas todas ao mesmo tempo. Esta é a norma que se vê, por exemplo, nos diversos planos alimentares redigidos pelas comissões de cardápios em empresas, escolas e hospitais, bem como nos contratos entre uma empresa de alimentação coletiva e uma empresa cliente. Neste tipo de documento, os redatores, ao definirem o tipo de alimentação que deve ser servida aos comensais, precisam o que, para aquele determinado tipo de coletividade, pode ser considerada uma "refeição normal". Considerando-se o plano individual, a norma social pode ser recuperada através da definição de uma "verdadeira refeição" dada pelo indivíduo quando questionado Para você, o que é uma verdadeira refeição?

Um exemplo desta questão pode ser observado em Fischler $(2003)^{6}$ que, ao analisar a alimentação em sete países, discute as diferentes estruturas de refeições, bem como as percepções distintas de "uma verdadeira refeição" que podem ser destacadas em diferentes culturas.

\footnotetext{
5 A expressão francesa prise alimentaire é traduzida em português como "tomada alimentar" e visa englobar a noção de consumo alimentar, tanto durante as refeições como fora das mesmas. A sua utilização surgiu a partir de discussões sobre a necessidade de se ter um termo neutro, que represente todos os momentos de apreensão de alimentos, sem a conotação negativa que, geralmente, acompanha a alimentação fora das refeições (por exemplo, em francês grignoter ou picorer e, em português, "lambiscar" ou "beliscar"). O termo, com este sentido, foi utilizado pela primeira vez em um relatório de pesquisa (Poulain et al., 1996) e publicado em Poulain (1998) ${ }^{17}$.
} 


\section{As opiniões}

Correspondem àquilo que declara pensar um indivíduo sobre uma prática ou um objeto ${ }^{16}$. A opinião é uma expressão verbal espontânea e consciente, positiva ou negativa, dos valores e das atitudes.

\section{Os valores}

São as representações, conscientes ou não, positivas ou negativas, associadas a uma prática ou a um objeto social ${ }^{16}$.

\section{As atitudes}

Correspondem ao conjunto de predisposições individuais em relação a um objeto ou a uma prática. Stoetzel $(2000)^{18}$ define a atitude como a "maneira pela qual uma pessoa se situa com relação a objetos ou práticas que são valorizados pelo gruposocial na qual ela esta inserida". As atitudes somente podem ser estudadas indiretamente, uma vez que elas se distinguem das opiniões pelo fato de não serem sempre verbalizáveis, nem sequer conscientes. Mas, nem por isso, são menos importantes na determinação dos comportamentos. A atitude se estuda propondo ao indivíduo uma série de práticas e solicitando que ele as classifique, por exemplo, no sentido das aceitáveis às não aceitáveis. Um exemplo de estudo deste tipo pode ser encontrado em Rozin et al. (1999) ${ }^{19}$.

\section{Os símbolos}

Eles são conjuntos de significações estruturadas e organizadas em sistemas de representações. Freqüentemente imperceptíveis à consciência dos comedores, os símbolos participam da expressão do tecido social e do sentimento de vinculação a um grupo ou, ao contrário, ajudam a definir as diferenças sociais. Um exemplo é a representação da expressão manger la cuisine que, numa tradução literal, significaria "comer a cozinha" e, conforme destaca Fischler (2003)6, somente tem significado para os franceses, que utilizam essa expressão para designar o tipo de alimentação que a pessoa consome. Mas, conforme salientado em Poulain $(1998)^{20}$, mesmo entre os franceses, uma questão desse tipo pode gerar diferentes interpretações, tais como, cuisine (ou alimentação) em termos: culinários (familiar, refinada...), de produtos (natural, biológica...), de cultura e identidade (tradicional, regional...), de condicionantes temporais ou econômicas (rápida, barata...), bem como em termos nutricionais (equilibrada, sem gorduras...). Outros exemplos podem ser encontrados em Garabuau-Moussaoui et al. $(2002)^{21}$.

Todas essas diferentes categorias de dados, definidas e exemplificadas (Quadro 1), apresentam um certo interesse. Elas constituem famílias de variáveis que permitem engajar o estudo sociológico do espaço social alimentar. Salientase que nenhuma delas sozinha pretende dar conta da complexidade do fato social alimentar sendo, para isto, necessário combiná-las. Outro destaque é que nas deformações submetidas aos dados comportamentais no curso da sua reconstituição, na defasagem eventual entre as práticas declaradas, as normas ou os valores em relação àquilo que realmente é posto em prática, reside um material sociológico de primeira importância. É nos cruzamento desses dados de natureza diferente que emerge o sentido das práticas e que se desenvolvem as reflexões sociológicas sobre os determinantes dos fatos sociais. As ciências cognitivas tentam, atualmente, compreender as lógicas que conectam as representações e as práticas ${ }^{22}$. Um grande número de contradições entre as diferentes pesquisas disponíveis sobre a alimentação contemporânea tem a sua origem na diferença de natureza dos dados sobre os quais elas se apóiam.

Destaca-se, ainda, que no estudo das práticas alimentares, o esforço de objetivação não é sempre finalizado pelos sociólogos, sem falar dos trabalhos conduzidos pelos não-sociólogos que 
utilizam os instrumentos sociológicos (questionários, entrevistas) sem, contudo, controlar os quadros teóricos que permitem distinguir o tipo de dado coletado. Esta situação foi abordada por Garine $(1980)^{5}$ que, considerando a realidade francesa de dados sobre alimentação, ressaltava a necessidade e a urgência de trabalhar com coleta de dados empíricos "O essencial de nossos conhecimentos sobre a alimentação contemporânea francesa é adquirido através de questionários nos quais a apresentação pode sugerir que se referem a observações diretas de fatos materialmente objetivos. Mas eles, na maioria das vezes, não representam nada, e este

Quadro 1. Os níveis do fato social alimentar: definições e exemplos.

\begin{tabular}{|c|c|c|}
\hline Níveis do fato social alimentar & Definições & Exemplos \\
\hline Práticas observadas & $\begin{array}{l}\text { Comportamento individual ou coletivo, externa- } \\
\text { lizado com a ajuda de técnicas audiovisuais de } \\
\text { registro. }\end{array}$ & $\begin{array}{l}\text { Composição da bandeja ou do prato. Itens que } \\
\text { compõem um carrinho de compras num supermer- } \\
\text { cado. }\end{array}$ \\
\hline Práticas objetivadas & $\begin{array}{l}\text { Práticas analisadas através dos traços que elas } \\
\text { deixam: fluxo econômico, fluxo de dejetos, etc. }\end{array}$ & $\begin{array}{l}\text { Quantidade de produtos vendidos em uma dada } \\
\text { zona geográfica. }\end{array}$ \\
\hline Práticas reconstruídas & $\begin{array}{l}\text { Rememoração assistida de práticas de compras } \\
\text { ou de consumo, a partir de uma grade de acom- } \\
\text { panhamento que permite um inventário sistemá- } \\
\text { tico das diferentes dimensões de uma prática. }\end{array}$ & $\begin{array}{l}\text { Reconstrução das compras, das práticas culinárias } \\
\text { ou das diferentes tomadas alimentares sob uma } \\
\text { dada unidade de tempo : dia, semana, mês, etc. }\end{array}$ \\
\hline $\begin{array}{l}\text { Práticas declaradas esponta- } \\
\text { neamente }\end{array}$ & $\begin{array}{l}\text { Reconstituição espontânea de uma prática sem } \\
\text { que as dimensões sejam sugeridas pelo pesqui- } \\
\text { sador. }\end{array}$ & $\begin{array}{l}\text { Respostas espontâneas a uma questão do tipo : } \\
\text { o que você fez...? }\end{array}$ \\
\hline Normas e modelos coletivos & $\begin{array}{l}\text { Expressão do que é uma prática considerada } \\
\text { "conveniente" e cuja não-observância resulta, } \\
\text { geralmente, em sanções mais ou menos explícitas. }\end{array}$ & $\begin{array}{l}\text { No Brasil, um "verdadeiro almoço" se compõe, } \\
\text { por exemplo, de arroz, feijão, alguma preparação } \\
\text { com carne, complemento, salada e sobremesa. }\end{array}$ \\
\hline Opiniões & $\begin{array}{l}\text { Representa o pensamento de um indivíduo ou } \\
\text { de um grupo sobre uma determinada prática. A } \\
\text { opinião é a expressão verbal das atitudes ou dos } \\
\text { valores. }\end{array}$ & $\begin{array}{l}\text { A afirmação de que "comer entre as refeições } \\
\text { não é bom para a saúde". }\end{array}$ \\
\hline Atitudes & $\begin{array}{l}\text { Conjunto de predisposições de um indivíduo em } \\
\text { relação a um objeto ou uma prática. A atitude } \\
\text { somente pode ser estudada indiretamente, e se } \\
\text { distingue da opinião pelo fato de não ser } \\
\text { freqüentemente verbalizada, mas determinada por } \\
\text { comportamentos. }\end{array}$ & $\begin{array}{l}\text { Analisa-se a atitude propondo-se ao indivíduo } \\
\text { uma série de práticas e lhe solicitando classificá- } \\
\text { las, por exemplo, entre aceitáveis e não aceitáveis. }\end{array}$ \\
\hline Valores & $\begin{array}{l}\text { Os valores são representações positivas ou } \\
\text { negativas, mais ou menos racionais, associadas a } \\
\text { uma prática ou a um produto. }\end{array}$ & $\begin{array}{l}\text { Comer muito pão aumenta a barriga ... } \\
\text { Comer arroz com feijão engorda... } \\
\text { Comer pão torrado não engorda... }\end{array}$ \\
\hline Sistemas simbólicos & $\begin{array}{l}\text { Conjunto de núcleos de sentido, mais ou menos } \\
\text { conscientes, estruturados e organizados em } \\
\text { sistemas de representações. }\end{array}$ & $\begin{array}{l}\text { Símbolo associado a um produto: a carne vermelha } \\
\text { sustenta, peru é comida de Natal, canja é comida } \\
\text { de doente... } \\
\text { Sistema de representações inconscientes de, por } \\
\text { exemplo, posições à mesa ou de sistemas de } \\
\text { cocção. }\end{array}$ \\
\hline
\end{tabular}


gênero de abordagem não pode substituir uma análise objetiva e quantificada da produção e do consumo de alimentos, a única apta a estabelecer os fatos e a poder compará-los".

\section{O MÉTODOE OS INSTRUMENTOS DE COLETA DEDADOS}

Os métodos e os instrumentos de coleta de dados podem ser concebidos especificamente para uma pesquisa ou pode-se utilizar técnicas já desenvolvidas em outros estudos, o que é especialmente interessante pela possibilidade de comparação. Destaca-se, contudo, a importância do cuidado da etapa de validação do instrumento de pesquisa, quando se trabalha com material idealizado para países de realidade e idioma diferentes. Discussões sobre a tradução de instrumentos de pesquisa em nutrição e saúde podem ser consultadas em Sartorius \& Kuyken $(1994)^{23}$ e Altenburg de Assis et al. (2002)24. Já as etapas para a validação do método e do instrumento de pesquisa para uma dada realidade podem ser consultadas em Morais \& Gimeno $(2002)^{25}$ e Rohrmann \& Klein $(2003)^{26}$.

A coleta de dados sociológicos pode ser feita a partir de seis grandes técnicas:

1) A observação participante: Muito próxima da abordagem etnográfica, ela consiste em se integrar a um grupo social e participar de sua vida, da maneira mais concreta possível, durante um período suficientemente longo que permita que o observador perca o seu estatuto de pesquisador e torne-se um membro do grupo tal como os outros. Este método pode ser desenvolvido de duas maneiras, a observação transparente, quando o grupo tem conhecimento do papel do pesquisador, e a observação opaca, quando o pesquisador esconde a sua verdadeira identidade atrás de um outro papel social (Juan, 1999) ${ }^{27}$. Um exemplo de utilização deste método pode ser encontrado em Garabuau-Moussaoui $(2002)^{28}$

2) A observação armada: Este método consiste em entrar em um contexto social com grades de leitura bem precisas que permitam perceber os fatos quando esses são produzidos, reparando os contextos e os acontecimentos que os precedem e que os seguem. A técnica do itinerário das práticas de Dominique Desjeux (1996) ${ }^{12}$ consiste, por exemplo, na reconstituição pela observação do "caminho que segue um alimento, desde a preparação para as compras, o local de compra e, depois, os sucessivos lugares onde ele é trabalhado e utilizado, tal como o refrigerador, o forno, o prato à mesa... até a lata de lixo".

3) O questionário: O questionário é um instrumento central na Sociologia, que permite a coleta de grandes quantidades de dados que serão objeto de tratamentos informatizados: dados de representações, de opiniões, de comportamentos declarados, de comportamentos reconstruídos. Ele permite trabalhar uma grande gama de variáveis.

Existem várias formas de administração de questionários ${ }^{(6)}$, dentre as quais comentaremos as de uso mais comum em Sociologia da Alimentação.

- Por entrevista pessoal: é o método considerado mais confiável, na medida em que ele é conduzido por entrevistadores treinados, permitindo a utilização de um grande número de questões e, sobretudo, de questionamentos mais complexos. Destaca-se, contudo, a necessidade de uma atenção particular para controlar o impacto dos papéis e do status dos entrevistadores. O fato de o entrevistador ser, por exemplo, médico, enfermeiro, nutricionista ou sociólogo pode, durante a condução da entrevista, induzir a desvios devido às representações que o entrevistado associa a esses profissionais.

- Por entrevista telefônica: este é um método conveniente à coleta de dados simples e

6 Alguns autores realizam inventários dos métodos utilizados em saúde e nutrição, tais como, Romon (2001)², Galand \& Hercberg $(1994)^{29}$ e Dwyer (1999) ${ }^{30}$. 
bem estruturados. Muito utilizado por institutos de pesquisa, ele apresenta vantagens de custo evidentes, mas é mal adaptado a certas formas de questões próprias das enquêtes alimentares, principalmente às questões que envolvem, por exemplo, a apresentação de uma lista ou de fotos de alimentos. Outro ponto a ser ressaltado é a maneira de falar do entrevistador, uma vez que a alimentação é, normalmente, alvo de regionalismos de linguagem. Um exemplo interessante desta questão é uma pesquisa transcultural sobre a alimentação em sete países que, em uma das suas etapas, contou com uma enquête realizada por telefone que foi centralizada em Paris (França). Durante o estudo piloto, observou-se a importância de que os entrevistadores, embora centralizados em uma mesma sala, fossem nativos dos países pesquisados e tivessem um linguajar adequado à região em que seria feita a pesquisa, a fim de evitar equívocos no momento da enquêté .

- Por auto-administração: neste caso o entrevistado preenche sozinho o questionário que Ihe é proposto, em lugares e em contextos diversos. O questionário pode lhe ser entregue na própria casa e recuperado alguns dias depois ou devolvido pelo correio após um acordo prévio. Essa solução, além de ser evidentemente mais econômica, apresenta também a vantagem de evitar as interferências entre o status social do entrevistador e do entrevistado, mas, com o inconveniente, principalmente em grandes escalas e com populações pouco motivadas, de resultar em uma seleção da amostra ou em dados incorretos, pois um segmento da população pode ter dificuldades em preenchê-lo. É possível minimizar essas limitações quando um questionário é autoadministrado no interior de instituições como escolas $^{31}$, indústrias ${ }^{32}$ ou instituições de saúde, devendo-se, todavia, ter o cuidado para que o peso da instituição não seja a origem de desvios nos dados. Enfim, a auto-administração pode ser realizada à distância utilizando recursos como o minitel, instrumento utilizado nos estudos SUVIMAX, cuja metodologia é explicitada em Hercberg et al. (1998)33, ou pela Internet.
Ainda na auto-administração de questionários, pode-se dispor de técnicas variadas de relato ou de reconstrução das práticas alimentares, explicitadas abaixo.

- O carnê alimentar é um documento préestruturado no qual os indivíduos anotam (às vezes após pesagem) as diferentes tomadas alimentares. Exemplos de utilização desse tipo de instrumento podem ser consultados em de Castro et al. $(1997)^{34}$ e Bellisle et al. (1999)35.

- As ferramentas de anamnese permitem ajudar o indivíduo a rememorizar o seu consumo alimentar. A reconstrução pode ser referente a períodos variados: recordatório de 24 horas, de três dias, de uma semana, e outros, como, por exemplo, em de Assis et al. (2003) ${ }^{14}$.

4) As entrevistas semi-estruturadas: As entrevistas podem ser individuais ou coletivas, quando se utiliza a técnica denominada grupos focais (focus groups), e permitem estudar as representações dos comedores e o sentido que eles dão às suas ações. A técnica de entrevista semi-estruturada consiste em "fazer falar" as pessoas quando interrogadas sobre um determinado tema, reformulado no decorrer do tempo para redirecionar a discussão, sem deter-se estritamente ao assunto de partida. As digressões são importantes porque permitem perceber as representações e os quadros de referência mais ou menos conscientes nos quais se manifestam as lógicas dos atores. Exemplos de utilização desta técnica relacionados à alimentação e à nutrição podem ser consultados em Eats... (2001) ${ }^{36}$; Sobral (2001)37; Dutra de Oliveira et al. (2002) ${ }^{38}$ e Bäckström et al. (2003) ${ }^{39}$.

5) As histórias de vida alimentar: Este método, inspirado naquele desenvolvido por Lalive d'Epinay $(1985)^{40}$, consiste em fazer o indivíduo reconstruir a sua história alimentar. Ele busca fazer emergir, dentre outras, as grandes transformações de práticas, de gostos, de estatuto ponderal, nos contextos biográficos dos entrevistados ${ }^{41}$.

6) O tratamento de dados secundários: Aqui se trata de utilizar dados já coletados para outros fins, dentro de outras lógicas de pesquisa: 
econômicas, demográficas, psicológicas, etnológicas, ou para positivar os fatos sociais ou para produzir reinterpretações.

Estas diferentes técnicas, resumidas (Tabela 1), permitem níveis distintos de eficácia na coleta dos dados. Por isso os programas de pesquisa costumam associar vários métodos de coleta, de acordo com os objetivos a serem alcançados.

\section{AS VIAS DE ACESSO AO ESPAÇOSOCIAL ALIMENTAR}

\section{As disponibilidades na escala das nações}

A Food and Agriculture Organization (FAO), órgão da Organização das Nações Unidas responsável pelas questões relativas à alimentação, desenvolveu um método para avaliar as disponibilidades alimentares no âmbito das nações. Elas são calculadas a partir de uma conta que envolve a relação "recurso-utilização" em cada país. "Indica-se, para cada produto alimentar, as quantidades produzidas, importadas e as variações de estoque. Para conhecer as quantidades utilizadas, distingue-se as quantidades exportadas, aquelas referentes à alimentação animal, às sementes, aos usos industriais alimentares e não alimentares. Estimam-se as perdas de estocagem e transporte e, finalmente, obtém-se um valor que corresponde às quantidades disponíveis para a alimentação humana" ${ }^{42}$. Esses valores são, então, divididos pela população do país e obtém-se assim a "ração alimentar média" de um habitante, permitindo comparações internacionais. É igualmente possível consolidar o conjunto desses dados para calcular a ração "do cidadão do mundo".

Esse tipo de dado evidencia os Modelos Agro-Nutricionais (MAN) bastante diferentes entre os países e as regiões do mundo. Uma tipologia de MAN proposta pela FAO apoiava-se na importância relativa das diferentes categorias de alimentos na ração média ${ }^{43}$. Ela foi estabelecida a partir dos alimentos de base, i.e., aqueles que

Tabela 1. Técnicas de coleta e dados sociológicos

\begin{tabular}{|c|c|c|c|c|c|c|c|c|c|}
\hline \multirow[b]{2}{*}{$\begin{array}{l}\text { Técnicas de } \\
\text { coleta }\end{array}$} & \multicolumn{7}{|c|}{ Tipos de dados } & \multirow[b]{2}{*}{ Valores } & \multirow[b]{2}{*}{ Símbolos } \\
\hline & $\begin{array}{c}\text { Práticas } \\
\text { observadas }\end{array}$ & $\begin{array}{c}\text { Práticas } \\
\text { objetivadas }\end{array}$ & $\begin{array}{l}\text { Práticas } \\
\text { reconstruídas }\end{array}$ & $\begin{array}{c}\text { Práticas } \\
\text { declaradas }\end{array}$ & $\begin{array}{l}\text { Normas } \\
\text { individuais }\end{array}$ & Opiniões & Atitudes & & \\
\hline $\begin{array}{l}\text { Observação } \\
\text { participante }\end{array}$ & + & & & & + & + & + & + & + \\
\hline $\begin{array}{l}\text { Observação } \\
\text { armada }\end{array}$ & + & & & & + & & + & & \\
\hline $\begin{array}{l}\text { Questionário } \\
\text { auto-administrado }\end{array}$ & & & +- & + & + & + & + & + & +- \\
\hline $\begin{array}{l}\text { Questionário por } \\
\text { entrevista }\end{array}$ & & & + & + & + & + & + & + & + \\
\hline $\begin{array}{l}\text { Entrevistas } \\
\text { semi-estruturadas }\end{array}$ & & & +- & + & + & + & + & + & + \\
\hline História de vida & & & +- & + & + & + & + & + & + \\
\hline $\begin{array}{l}\text { Tratamento de } \\
\text { dados secundários }\end{array}$ & & + & & & + & & & + & + \\
\hline
\end{tabular}


aportam a principal parcela da ração energética, distinguindo, assim, seis grandes tipos de MAN.

O primeiro MAN é centrado sobre os produtos de origem animal (carnes e produtos lácteos). Ele está presente em 30 países, ocidentais na sua maioria, e corresponde a 13\% da população mundial. O segundo MAN baseia-se nos produtos derivados do trigo (pão, macarrão, entre outros) sendo utilizado em 52 países que agrupam $18 \%$ da população mundial. O terceiro, à base de milho, refere-se a 20 países (principalmente da América do Sul) e engloba $6 \%$ da população global. O quarto, ainda do tipo cerealista, utiliza sorgo como alimento central e envolve 6 países africanos, representando 3\% dos habitantes do mundo. O quinto organiza-se em torno do arroz e representa o modelo mais utilizado, posto que está presente em 43 países, sobretudo asiáticos, sendo praticado por mais de $58 \%$ da humanidade. Enfim, o sexto modelo agro-nutricional é à base de raízes, de tubérculos (batatas, mandioca, entre outros). É encontrado em 14 países que representam somente $2 \%$ da população mundial.

Torna-se possível afinar esses modelos agro-nutricionais pelo cálculo dos pesos relativos das diferentes categorias de alimentos em cada grupo ${ }^{43}$.

Neste mesmo contexto, há o material encontrado em obras como o Atlas da Alimentação no Mundo ${ }^{44}$, que disponibiliza informações sobre os elos da cadeia alimentar, estruturadas a partir das bases disponíveis para todos os países do mundo.

Essas séries estatísticas permitem realizar comparações, tanto no tempo, para entender as evoluções, quanto no espaço, para compreender a diversidade das formas de alimentação humana. Elas oferecem também a possibilidade, no interior de um dado país, de situar os subgrupos em relação ao modelo médio do país tratado, analisando, dessa forma, a dispersão social.

No entanto, esses tipos de dados apresentam um certo número de dificuldades e de suscetibilidades no tratamento das informações.
O primeiro problema é de ordem metodológica, uma vez que a simples medição da população já coloca dificuldades importantes. As fontes variam consideravelmente de um país a outro, tornando a avaliação das disponibilidades alimentares um verdadeiro quebra-cabeças. Como levar em conta as produções informais (que não passam pelo mercado), assim como a alimentação proveniente de pesca ou caça? Como medir as perdas de conservação e de preparação, bem como os dejetos das diferentes etapas do ciclo de transformação e os restos de consumo (que sobram nos pratos)? Esses restos variam consideravelmente de uma cultura para outra e entre níveis de desenvolvimento econômico diferentes. As quantidades de alimentos jogados fora pelas sociedades ocidentais mais ricas são cada vez mais significativas e não têm nada em comum com aqueles restos em países onde os alimentos são mais raros. Por exemplo, na França, até 20 anos atrás, em função da mentalidade de não-desperdício gerada pelas penúrias de duas guerras mundiais, praticamente todo o pão comprado era consumido. Porém, atualmente, pesquisas demonstram que a quantidade de pão consumido é inferior à metade do pão adquirido.

Destaca-se ainda que, neste método, a distinção entre a alimentação humana e a alimentação dos animais domésticos nem sempre é bem demarcada e conduz, principalmente nos países mais desenvolvidos economicamente, a avaliações superestimadas. Enfim, e sobretudo considerando a Sociologia da Alimentação, esses tipos de dados médios não permitem a compreensão direta das diferenciações sociais internas de um país.

O segundo problema é referente à utilização deste tipo de informação, pois, como esses dados são geralmente utilizados para calcular as ajudas internacionais, certos países podem ter interesse em super avaliar as suas populações e subavaliar as suas produções alimentares.

O retratamento das disponibilidades alimentares realizado por equipes pluridisciplinares, 
compreendendo, por exemplo, economistas e nutricionistas, permitiu a realização de análises dinâmicas da estrutura dos aportes energéticos da ração alimentar. Elas evidenciam, por exemplo, uma estabilidade da parte protéica da ração e uma evolução inversa da parte referente a lipídios e carboidratos, os primeiros aumentando regularmente em detrimento dos segundos.

\section{Entrada pelas compras}

Esta é a abordagem dos estudos ditos "de consumo" no sentido econômico. Nela registram-se os dados correspondentes às compras reais, tanto às observadas de maneira direta - COmo no caso das análises do conteúdo dos carrinhos de supermercado ${ }^{45}$ quanto às observadas através das variáveis macro e microeconômicas, por exemplo, de uma determinada cadeia de alimentos ou o volume de vendas de uma loja ${ }^{46,47}$. Historicamente a mais antiga, essa via de entrada permitiu a Engel e a Le Play e seus discípulos a formulação de algumas grandes leis sobre a evolução da estrutura dos orçamentos domésticos ${ }^{48,49}$. Ela oferece, atualmente, material de trabalho sobre os orçamentos e sobre as tendências de consumo de certos bens econômicos, sejam eles produtos ou serviços. Esse tipo de pesquisa pode ser conduzido por organismos públicos de estatística (IBGE, INSEE) ou por empresas privadas que realizam painéis de evolução de consumo para diversos setores econômicos.

Esses dados, geralmente mais precisos e mais detalhados que as disponibilidades citadas no item anterior, permitem o cruzamento com variáveis sociológicas (sexo, idade, categoria socioprofissional, por exemplo), com atitudes, opiniões, normas, valores ou, dependendo do quadro teórico, com variáveis de integração como habitus ${ }^{50}$, o tipo de vida ${ }^{51}$, o estilo de vida ${ }^{52}$, ou, ainda, as lógicas de ação. No entanto, ainda que esses estudos se denominem estudos de consumo, eles, na verdade, representam estudos de compras. Salienta-se que, mesmo que os alimentos comprados representem um consumo econômico, eles não representam automaticamente um consumo alimentar. Assim, essa via de entrada apresenta alguns pontos sensíveis.

Na análise de painéis de consumo, o primeiro ponto refere-se à modificação do valor simbólico de certos produtos, que transforma muito mais rapidamente os comportamentos de uso do que as práticas de compra. Voltando ao exemplo do pão, já citado, a análise dos fluxos econômicos demonstra que os franceses consomem hoje muito menos pão do que há cinqüenta anos: 125 gramas por pessoa por dia em 1950 e somente 60 gramas em 1995, de acordo com o l'Annuaire statistique de la France 1999(7). Mas esta abordagem que analisa as compras mascara parcialmente o fenômeno, uma vez que, conforme já mencionado, a metade do pão comprado vai para o lixo, o que seria impossível antigamente devido ao status simbólico e aos valores ligados a esse produto. De uma maneira geral, o estudo dos restos alimentares representa uma possibilidade de leitura privilegiada da modificação do estatuto simbólico dos alimentos, ao mesmo tempo que representa um contraponto necessário para aliar as práticas aos dados obtidos pela via de análise de compras.

O segundo ponto sensível esta relacionado às práticas de autoconsumo, fenômeno que é definido, em economia agroalimentar, "como a parte da produção que, em um local de exploração agrícola, não é vendida mas utilizada pelos habitantes da fazenda para suas necessidades pessoais" 53 . Com efeito, os alimentos consumidos por um ator social não transitam todos, nem em todas as ocasiões pelo "mercado". O caso do autoconsumo alimentar entre os agricultores é bem estudado ${ }^{54,55}$, mas o autoconsumo toca outras categorias sociais e não se reduz

\footnotetext{
7 No entanto, as formas de contabilidade das disponibilidades alimentares não variam tão rapidamente quanto a oferta de produtos. Neste caso, por exemplo, os pães de forma e os pães congelados não entraram nas estatísticas.
} 
somente às formas que ele toma nas populações agrícolas. $O$ autoconsumo existe, igualmente, nas populações não agrícolas, e se manifesta em diversas formas:

- Cultivo de hortas e pomares: atividade de lazer importante em várias sociedades, exemplo francês em Poulain (1998) ${ }^{20}$.

- Certas práticas de pequenas criações (galinhas, porcos, coelhos) ou mesmo da criação inscrita em lógicas de festividades (peru de Natal, no Brasil) ou de busca de qualidade. Esta última questão envolve, por exemplo, pessoas que, em plena crise da patologia denominada popularmente "vaca louca", começaram a criar animais para seu próprio consumo, à margem de toda a regulamentação sobre criação e abate.

- Atividades de colheita silvestre, pesca e caça inscritas na categoria atividades de lazer ${ }^{56}$.

Um exemplo de análise de autoconsumo conduzido de maneira detalhada pode ser encontrado em Lambert (1997) $)^{57}$. Enfim, para compreender as lógicas de compra e de consumo, certos estudos de Sociologia da Alimentação trabalharam com as práticas domésticas ${ }^{22,54,58} \mathrm{e}$ os comportamentos alimentares. Todavia, conforme já apontado em vários momentos neste artigo, vieses podem ser identificados em tais estudos pois, na maioria das vezes, eles não apresentam dados factuais (objetivamente observados) mas dados declarados (aquilo que o entrevistado pretende fazer). Assim, coloca-se novamente o problema da natureza, do estatuto e da coerência entre o que se pretende fazer e o que se faz realmente.

\section{Entrada pelas práticas domésticas}

Com esta abordagem, penetra-se no fenômeno alimentar pelas atividades domésticas e sua organização: práticas de compras, de autoprodução, de preparação e de consumos alimentares. Ela parte do princípio de que a atividade doméstica não é somente uma unidade de consumo, mas uma unidade de autoprodução de alimentos brutos (produção em hortas e pomares, pesca, caça, trabalho de artesões da agricultura e da pecuária), e também de autoprodução culinária que corresponde às atividades de preparação de alimentos, sobretudo preparações cotidianas. Em face da oferta agroalimentar contemporânea, para o desenvolvimento das atividades domésticas tem-se a escolha de, ou cozinhar a partir de produtos brutos, de acordo com os métodos tradicionais, ou comprar produtos semi-elaborados nos quais certas etapas de fabricação (descascar, picar, pré-cozinhar) já foram realizadas, ou ainda de utilizar pratos prontos para o consumo. Torna-se óbvio que, em uma perspectiva econômica, quando as preparações e transformações são realizadas no interior dos domicílios, elas são criadoras de um valor agregado, o que não ocorre quando se compra produtos acabados, produzidos industrialmente.

O ponto forte deste tipo de estudo é de evidenciar o espaço socioeconômico de desdobramento das estratégias alimentares, seja nas lógicas a duas dimensões - exemplo da teoria de Gary Becker (1965) $)^{59}$ que coloca a decisão de compra como uma arbitragem entre a economia de tempo e a economia de valor - , seja nas $n$ dimensões que integram as variáveis sociológicas suplementares.

A reconfiguração atual das compras em certos domicílios, que se traduz por uma diminuição do valor consagrado à alimentação em relação ao valor total das despesas domésticas, não significa necessariamente uma degradação qualitativa do consumo, como pode induzir uma análise econômica sumária. Esse fenômeno pode ser explicado, por exemplo, em contextos nos quais o tempo já não é o fator mais raro (aposentadoria, ou desemprego, por exemplo), o que leva ao deslocamento das compras de produtos prontos para produtos brutos, não incluindo o valor agregado.

O consumo de preparações culinárias pode ser igualmente diferenciado. Assim, as conservas ou os pratos preparados e congelados serão consumidos posteriormente e se inscrevem em 
uma gestão do tempo a longo termo ou, ainda, serão dados ou trocados dentro de lógicas de solidariedade. Nesses casos, os domićlios que compram e cozinham não são os mesmos que consomem. Alguns estudos mostram como o trabalho doméstico, incluindo a preparação da comida, é uma das formas de expressão da solidariedade familiar ${ }^{60,61}$

Os trabalhos realizados nessa perspectiva se reagrupam nas denominações de pesquisas domiciliares ou pesquisas domésticas. Os dados importantes aqui são não somente os comportamentos de compra (lugar, ritmo, modalidades) mas também as características do espaço doméstico: equipamentos domésticos, inventários de produtos alimentares estocados, etc. Como para todos os estudos ditos de consumo, esses dados são analisados através da perspectiva das variáveis sociológicas clássicas e das lógicas de ação. Essas enquêtes abordam, igualmente, as praticas à mesa, mas, na maioria das vezes, a partir de dados declarativos (comportamentos reconstruídos ou declarados, opiniões, atitudes, valores).

Os limites deste tipo de abordagem podem ser explicitados em três grupos. Primeiramente, as práticas à mesa são coletadas, normalmente de forma verbal, e a qualidade dos dados reconstruídos depende muito do instrumento de coleta adequado. Em segundo lugar, destaca-se que o espaço doméstico não é o único local de consumo de alimentos; no mundo todo, as pesquisas demonstram a tendência crescente do consumo de alimentação fora de casa. Enfim, uma parte importante desta alimentação fora de casa pode não estar sendo analisada, por encontrar-se ausente dos estudos de compras. Assim, Lambert (1992) ${ }^{62}$ ressalta que elas podem não estar figurando nas categorias tradicionais das estatísticas oficiais que consideram as análises domésticas por não se realizarem nos domicílios - mesmo que elas representem, por exemplo, para a população ativa francesa, quase $60 \%$ das tomadas alimentares fora das refeições ${ }^{9}$.

\section{Entrada pelas práticas alimentares}

Três grupos de estudos podem ser destacados neste item, aproveitados em função dos objetivos esperados.

Os estudos que visam produzir balanços nutricionais e os que buscam analisar os consumos individuais, conduzidos, na maioria das vezes, por nutricionistas ou epidemiologistas, interessam-se pelo consumo alimentar para calcular os aportes energéticos e os aportes em diferentes macro e micronutrientes. Os problemas metodológicos que eles encontram bem como as diferentes técnicas de coleta são objeto de vários estudos, como já destacado 2,29,30. Já nos estudos que buscam identificar e entender as formas de tomadas alimentares, procura-se identificar as estruturas das diferentes refeições e a organização das jornadas alimentares $9,20,63$

A via de entrada é, aqui, o consumo alimentar no seu senso estrito, quer dizer, o comportamento alimentar, as práticas à mesa e as suas representações. As dificuldades materiais de coleta de dados comportamentais explicam, em grande parte, a pequena quantidade de informações disponíveis sobre esta questão.

Ressalta-se, ainda, a existência de pesquisas que abordam os restaurantes comerciais como um local de "consumo de alimentos". Mas, na maioria das vezes, mesmo se essas pesquisas se aproximam das práticas alimentares, elas destacam, sobretudo, a categoria de entrada pelas compras. Contudo, como no restaurante a compra é imediatamente seguida pelo consumo, destacase que se pode abordar, também, entrando no fenômeno alimentar pelo final (o consumo) e adotando um ponto de vista suscetível de considerar as lógicas comportamentais na perspectiva da escala social da alimentação, qual seja, interação entre os atores, representação simbólica dos alimentos e das práticas, decodificação dos traços de passagem dos produtos nos diferentes canais, etc.

Assim, os dados com entrada pelas práticas alimentares podem ser coletados: 
- No âmbito das unidades de alimentação comercial ou coletiva, pela observação concreta dos cardápios consumidos, da composição das bandejas, do tempo passado, dos restos após a refeição, dos horários, do contexto de socialização, ${ }^{9,20}$;

- No universo familiar, seja pela observação etnológica participativa ${ }^{12}$, seja pelas técnicas de registro automático (através de câmaras de fotografia ou vídeo na cozinha, na sala de refeições e outros) ou seja pelas técnicas de reconstituição de dados (questionários de freqüência variada, como já exemplificado anteriormente).

\section{O método dos itinerários de consumo}

Estruturado pelo antropólogo do consumo Dominique Desjeux, este método (Figura 2), tem por objetivo compreender as utilizações feitas de um produto. Ele consiste em seguir o indivíduo ao longo do itinerário que vai desde a preparação para a compra até o consumo de um produto ou serviço. "Baseando-se mais nas práticas dos indivíduos do que nas suas motivações ou intenções, ele permite reconstituir o que condiciona suas escolhas, considerando as estruturas do cotidiano. Ele pesquisa, no interior dessas estruturas, as margens de manobra dos indivíduos, a parte de rotina e de mudanças que organiza os hábitos domésticos" ${ }^{64}$. A técnica consiste em observar as modalidades de decisão, de escolha, de armazenamento, de preparação e outros. Neste sentido, sete pontos de observação são destacados: a construção da decisão em casa, com as diferentes interações que a acompanham; o deslocamento até o local de compra; o ato da compra, com as suas interações sociais e as interações homem/objeto; o retorno e a estocagem

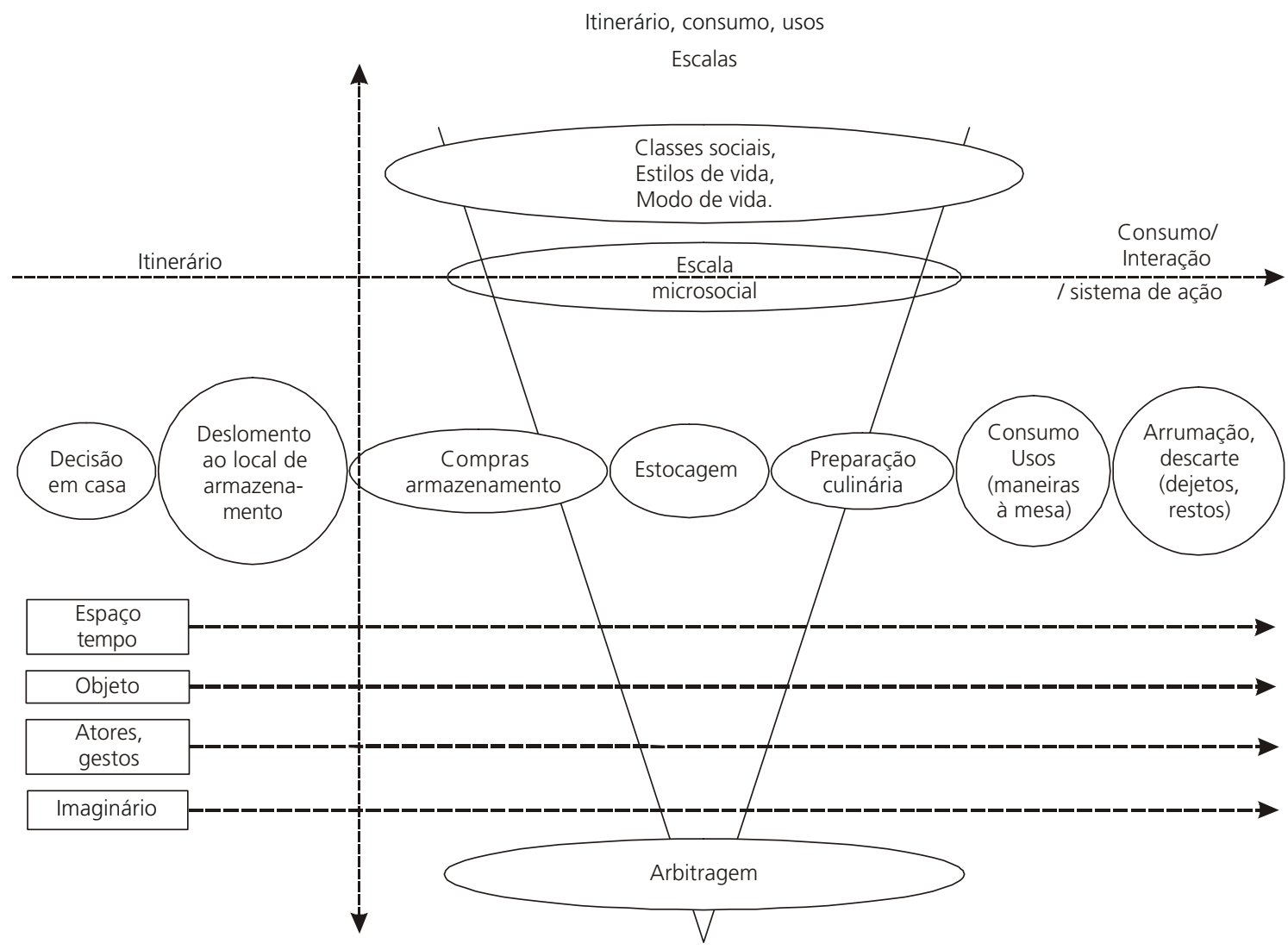

Figura 2. O método dos itinerários de consumo. Fonte: Desjeux (1998) ${ }^{64}$. 
doméstica; a preparação culinária; o consumo, práticas e maneiras à mesa; a arrumação final e o tratamento dos dejetos.

A cada etapa, observa-se como os produtos entram nas categorizações sociais que são condicionantes fortes para a evolução do comportamento do consumidor. O autor observa que "cada produto é associado a uma estrutura estável de práticas cotidianas, a um imaginário simbólico e a normas sociais em termos de representar socialmente frente aos outros [...] 0 interesse da abordagem pelos itinerários é, então, de recordar [...] que as escolhas dos consumidores não se limitam somente a julgamentos, mas se inscrevem nos jogos sociais estratégicos, emocionais e simbólicos".

As vias de acesso e os níveis de observação do fenômeno estão esquematizadas no Anexo.

\section{OS DESCRITORES DO COM PORT A MENTO ALIMENTAR}

A positivação das práticas alimentares, quer seja pela observação, pela objetivação indireta ou pela reconstrução, supõe a utilização de descritores suscetíveis de permitir a percepção das diferentes dimensões dessas práticas (Figura 3). Herpin $(1988)^{58}$ destaca cinco dimensões das práticas alimentares que podem servir de ponto de partida nesta questão, a saber, a concentração, a implantação temporal, a sincronização social, a localização e a ritualização.

Dessas cinco dimensões, parece-nos que a ritualização compreende uma dimensão macro, traduzindo todo um conjunto de lógicas de funcionalidade social e de contexto aos quais correspondem formas particulares do aparelho normativo alimentar ${ }^{65,66} \mathrm{e}$, nesse sentido, não podem ser utilizados como descritores simples.

Dentre as outras quatro trabalhadas a seguir, a concentração compreende a idéia de estrutura da refeição e do número de tomadas alimentares diárias. Parece ser necessário, aqui, distinguir duas unidades empíricas e semânticas, definidas pelos próprios sujeitos:

- As refeições (café da manhã, almoço e jantar), tomadas alimentares fortemente instituídas e sobre as quais pesam regras sociais claramente definidas.

- As tomadas alimentares fora das refeições, bem menos instituídas, representadas pelos lanches e aperitivos, mas também pelos consumos alimentares não codificados, que podem ser sólidos ou líquidos e que se reagrupam, talvez, sob o termo "lambiscar ou beliscar" que costuma apresentar, tanto em francês como em português, uma conotação negativa.

Propõem-se, assim, como já citado anteriormente, a utilização do termo genérico "tomada alimentar", que pode se decompor em "refeição" e "fora da refeição", e que apresenta a vantagem de ser neutro, isto é, não apresentar uma conotação a priori. Entenda-se, então, que tomada alimentar representa "toda a ingestão de produtos sólidos e líquidos que têm um valor energético". No decorrer de um dia, as diferentes refeições e outras tomadas alimentares combinam-se para formar a "tomada alimentar diária ou cotidiana". Assim, essa noção de tomada alimentar diária postula a existência de uma interdependência entre as diferentes tomadas no decurso de um dia.

Torna-se possível distinguir, então, para uma tomada alimentar, sete dimensões, formadas por componentes, a partir dos quais serão construídos os descritores que poderão ocupar a posição de variáveis (Figura 3).

- A dimensão temporal: Ela caracteriza o momento do dia (horário) e a duração das tomadas alimentares.

- A estrutura da tomada alimentar: Ela compreende, para cada refeição, o número de tomadas e a sua combinação - por exemplo - (a) arroz/feijão/prato principal mais complemento/salada/sobremesa; (b) prato principal mais complemento/salada; (c) prato principal/sobremesa - e para as tomadas fora das refeições, o número e a natureza da tomada - liquida, sólida ou combinada. 
1 - Temporal

2 - Estrutural
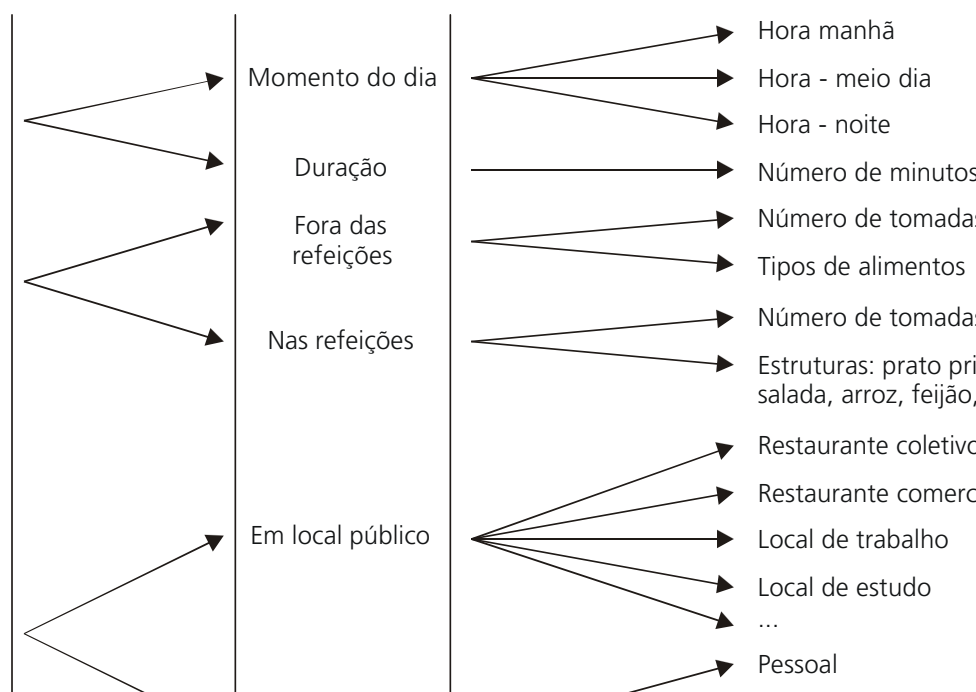

3 - Espacial

4 - Lógica de escolha

5 - Meio Ambiente Social

6 - Posição Corporal

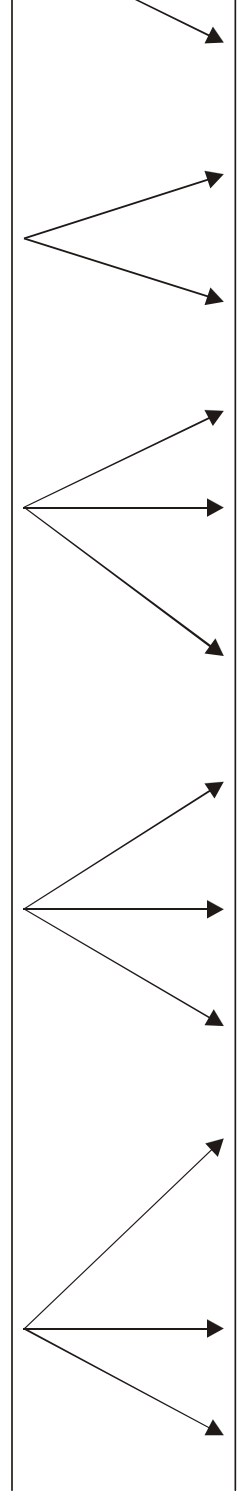

Em uma casa

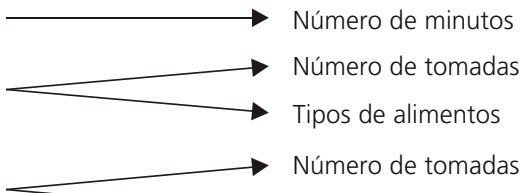

$\rightarrow$ Estruturas: prato principal, salada, arroz, feilão, etc.
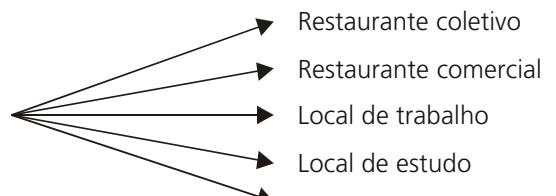

$\longrightarrow$ De um amigo

$\rightarrow$ Oferta fechada

Natureza

Delegada

$\rightarrow$ Oferta aberta

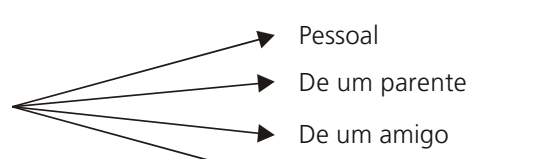

Ausente
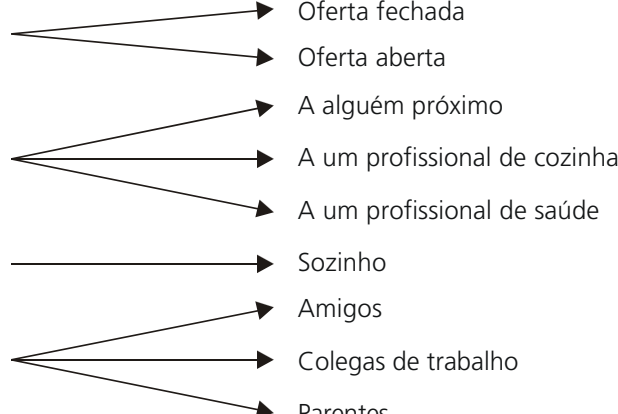

Número

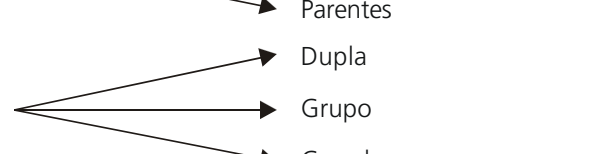

Em pé

$\rightarrow$ Grande grupo

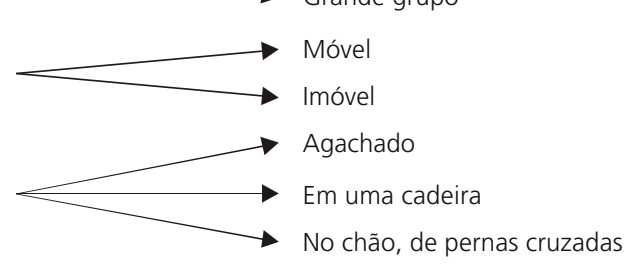

Sentado

$\rightarrow$ No chão, de pernas cruzadas

Deitado

Modo de pegar

o alimento

7 - Maneiras à mesa
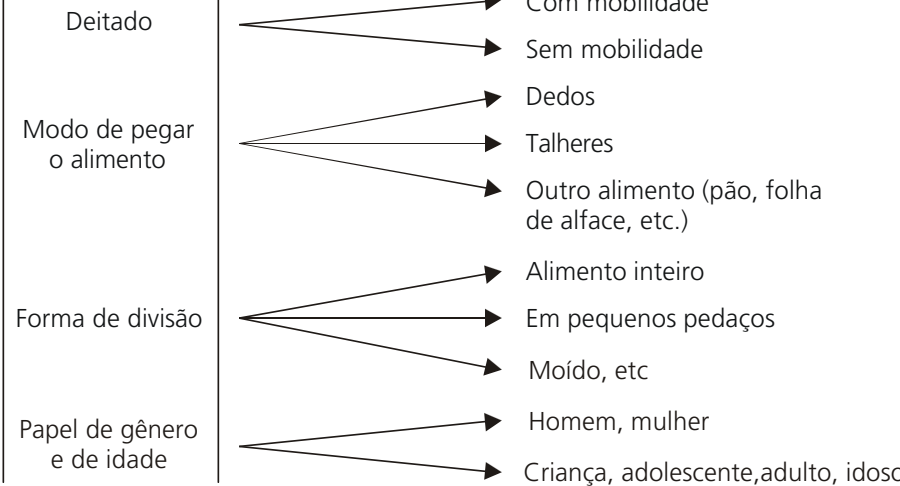

Figura 3. Os descritores das práticas alimentares. 
- A dimensão espacial: Uma primeira distinção se opera entre as tomadas alimentares ocorridas em casa e aquelas fora de casa, que são, elas mesmas, objeto de subcaracterizações: tipo de restaurante para as tomadas fora de casa e natureza do domicilio (pessoal, parente, amigo...) para as tomadas em casa.

- A lógica de escolha: Refere-se a observar se a pessoa decidiu sozinha o que ele iria consumir em uma possibilidade de escolha mais ou menos aberta, ou se ele delegou a alguém esta responsabilidade (parente ou amigo, profissional de cozinha ou de saúde).

- O meio ambiente social: A tomada alimentar pode ocorrer em um contexto solitário ou socializado, no qual se estudará a natureza e o número de pessoas presentes.

- A posição corporal: Durante o ato de consumo alimentar, o indivíduo pode estar em pé e, neste caso, móvel ou imóvel; sentado à mesa, acocorado, sentado sobre as pernas ou, ainda, deitado, com ou sem mobilidade.

- As maneiras à mesa: Referem-se às diferentes formas de apresentação e de tratamento do alimento no momento da tomada alimentar, destacando-se os diferentes modos de pegar e dividir o alimento, bem como o papel do gênero e da idade das pessoas no momento de comer.

O conjunto desses descritores permite não somente estudar a alimentação no interior de uma mesma cultura mas, também, em uma perspectiva comparativa, de destacar as diferenças alimentares de uma cultura para outra.

\section{O N CLUS Ã O}

A Sociologia da Alimentação tem por objeto as formas de investimento do social no espaço de liberdade deixado aos homens após as imposições das condicionantes biológicas e ecológicas . Assim, o espaço social alimentar é um conceito sociológico que encaminha para a análise da alimentação submetida às influências dos determinantes sociais.

A apresentação, aos colegas engajados no estudo da nutrição humana, das dimensões do espaço social alimentar ${ }^{8}$ do estudo das modalidades de construção e de coleta das variáveis sociológicas apresenta um duplo objetivo. Ela busca permitir a tomada de consciência da medida da complexidade científica do tema e da impossibilidade de reduzir o comportamento humano a somente uma das suas dimensões, seja ela fisiológica, psicológica ou sociológica. Então, graças a um melhor conhecimento recíproco dos instrumentos e das problemáticas, graças a uma verdadeira inculturação recíproca, espera-se contribuir para a promoção de uma abordagem pluridisciplinar da alimentação, considerando as vias já clássicas dos estudiosos da Nutrição e a via engajada por Edgar Morin na Sociologia.

\section{REFERÊ N CIAS}

1. Monteiro CA, Mondini L, de Souza AL, Popkin BM. The nutrition transition in Brazil. Eur J Clin Nutr 1995; 49(2):105-13.

2. Romon M. Evaluation de l'apporte alimentaire. In: Basdevan A, Laville M, Lerebours E. Traité de nutrition clinique de l'adulte. Paris: Flammarion; 2001. p.109-20.

3. Sichieri R. Dietary patterns and their associations with obesity in the Brazilian city of Rio de Janeiro, Brasil. Obes Res 2002; 10(1):42-8.

4. Mead M. The probleme of changing food habits. In: The problem of changing food habits. Report of the commitee on food habits 1941-1943. Bullettin of National Research Council, National Academy of Sciences, 108, 1943

5. Garine (de) I. Pour une anthropologie alimentaire. Ethnologie française: usages alimentaires des français 1980, n.3, t. X.

6. Fischler C. Alimentation, corps et santé, une approche transculturelle. Symposium OCHA. Paris: Editions Odile Jacob, 2003 (no prelo). 
7. Aron J-P. Le mangeur du 19 ème. Paris: Laffont; 1976.

8. Poulain J-P, Proença RPC. O espaço social alimentar: um instrumento para o estudo dos modelos alimentares. Rev Nutr 2003; 16(3):145-56.

9. Poulain J-P, Delorme J-M, Gineste M, Laporte C. Les nouvelles pratiques alimentaires, entre commensalisme et vagabondage. Dossier de recherche programme «Aliment Demain» du Ministère de l'Agriculture de la Pêche et de I'Alimentation et du Ministère de I'Education Nationale, de la Recherche et de la Technologie; 1996. 198p.

10. Poulain J-P. Manger aujourd'hui, Attitudes, normes et pratiques. Toulouse: Privat; 2001.

11. Poulain J-P. The contemporary diet in France: "de-structuration" or from commensalism to "vagabond feeding". Appetite 2002; 39:43-55.

12. Desjeux D. L'ethnologie, une méthode pour comprendre les comportements alimentaires domestiques. In: Desjeux J-F, Hercberg S. (dir.) La nutrition humaine, la recherche au service de la santé. Paris: INSERM-Nathan; 1996.

13. Corbeau J-P, Poulain J-P. Penser I'alimentation, entre imaginaire et rationalités. Toulouse: Privat; 2002.

14. de Assis MAA, Kupek E, Nahas MV, Bellisle F. Food intake and circadian rhythms in shift workers with a high work load. Appetite 2003; 40(2):175-83.

15. Durkheim E. Les formes élémentaires de la vie religieuse (1894). Paris: PUF; 1998.

16. Maisonneuve J. Introduction à la psychosociologie. Paris: PUF; 1973.

17. Poulain J-P. La modernité alimentaire, pathologie ou mutations sociales? Cahiers de Nutr Diét 1998; 33(6):351-8.

18. Stoetzel J. La psychologie sociale. Paris: Flammarion; 2000.

19. Rozin P, Fischler C, Imada S, Sarubin A, Vrzeniewski A. Attitudes to food and the role of food in life in the Etats-Unis, Japan, Flemish Belgium and France: possible implications for that diet-health debate. Appetite 1999; 33(2):163-80.
20. Poulain J-P. Les jeunes seniors et leur alimentation. Paris: Cahiers de I'OCHA, n.9; 1998.

21. Garabuau-Moussaoui I, Palomares E, Desjeux D. Alimentations Contemporaines. Paris: L'Harmattan; 2002.

22. Lahlou S. Penser manger. Paris: PUF; 1998.

23. Sartorius N, Kuyken W. Translation of health status instruments. In: Orley J, Kuyken W, editors. Quality of life assessment: international perspectives. Heidelberg: Springer Verlag; 1994. p.3-18.

24. Altenburg de Assis MA, Bellisle F, Kupek E, Passos M, Sachs A, Proença RPC, Fagundes R, Salles RK, Zeni LAZ. Adaptation of a weekly food diary in Brazil. Int J Obes 2002; 26(1):S34.

25. Morais VLA. Gimeno SGA. Reprodutibilidade e validade do questionário de freqüência de consumo de alimentos. Rev Saúde Pública 2002; 36(4): 505-12.

26. Rohrmann S, Klein G. Validation of a short questionnaire to qualitatively assess the intake of total fat, saturated, monounsaturated, polyunsaturated fatty acids, and cholesterol. J Hum Nutr Diet 2003; 16(2):111-7.

27. Juan S. Méthodes de recherche en sciences sociohumaines. Paris: PUF; 1999.

28. Garabuau-Moussaoui I. Cuisine et indépendances, jeunesse et alimentation. Paris: L'Harmattan; 2002.

29. Galan P, Hercberg S. Méthodes de mesure de la consommation alimentaire et techniques des enquêtes alimentaires. Cahiers de Nutr Diét 1994; 30.

30. Dwyer J. Dietary assessment. In: Shils M, Olson JA, Shike M, Ross AC. Modern Nutrition in health and disease. 9th ed. Philadelphia: Lippincott Williams \& Wilkins, 1999.

31. Fischler C. Le repas familial vu par les 10-11 ans. Paris: Cahiers de I'OCHA n 6; 1997.

32. Barros MVG, Nahas MV. Comportamentos de risco, auto-avaliação do nível de saúde e percepção de estresse entre trabalhadores da indústria. Rev Saúde Pública 2001; 35(6):554-63.

33. Hercberg S, Preziosi P, Briancon S, Galan P, Triol I, Malvy $D$, et al. A primary prevention trial using 
nutritional doses of antioxidant vitamins and minerals in cardiovascular diseases and cancers in a general population: the SU.VI.MAX study-design, methods, and participant characteristics. SUpplementation en VItamines et Mineraux AntioXydants. Control Clin Trials 1998; 19(4): 336-51.

34. de Castro J, Bellisle F, Dalix AM, Feunekes GIJ. Culture and meal patterns: a comparison of the food intake of free-living American, Dutch, and French students. Nutr Res 1997; 17:807-29.

35. Bellisle F, Dalix AM, de Castro JM. Eating patterns in French subjects studied by the "Weekly Food Diary» method. Appetite 1999; 32:46-52.

36. ETATS généraux de I'alimentation. Que voulons nous manger? Manger...en confiance, pour se faire du bien, pour se faire plaisir. Toulouse: Mission d'animation des Agrobiosciences; 2001.

37. Sobal J. Sample Extensiveness in qualitative nutrition education research. J Nutr Educ 2001; 33:184-92.

38. Dutra de Oliveira JE, Moreira EAM, Portella O, Berezovsky MW. Normas e guias alimentares para a população brasileira: delineamentos metodológicos e critérios técnicos. São Paulo: Instituto Danone; 2002.

39. Bäckström A, Pirttilä-Backman A-M, Tuorila H. Dimensions of novelty: a social representation approach to new foods. Appetite 2003; 40(3): 299-307.

40. Lalive d'Epinay C. Récits de vie et projet de connaissance scientifique (ou que faire de la subjectivité?). Recherches Sociologiques 1985; 16(2):237-49.

41. Corbeau J-P. Essai de reconstruction utopique des formes et des jeux du manger. Thése d'état de Sociologie sous Direction de Jean Duvignaud, publicado sob o título "Le mangeur imaginaire", Paris: Métaillé; 1991.

42. Périssé J. Typologie des disponibilités alimentaires par pays en 1990 basée sur un critère énergétique. In: Desjeux J-F, Hercberg S. La nutrition humaine, la recherche au service de la santé. Paris:INSERM-Nathan; 1996.
43. Malassis L, Padilla M. Économie agro-alimentaire. Paris: Cujas; 1987.

44. Millstone E, Lang T. Atlas de l'alimentation dans le monde. Paris: Autrement; 2003.

45. Herpin N. Alimentation et régionalisme. Données sociales INSEE. 1984: 340-1.

46. Combris P. Les grands traits de l'évolution de la consommation alimentaire en France 1956-1976. Académie d'Agriculture de France1980; 12: 1273-84.

47. Combris P. La consommation alimentaire en France de 1949 a 1988: continuité et ruptures. In: Eizner N. Voyage en alimentation. Paris: ARF Editions; 1995

48. Herpin N, Verger D. La consommation des français. Paris: La découverte; 1991.

49. Poulain J-P. Sociologies de I'alimentation. Paris: PUF; 2002.

50. Bourdieu P. La distinction. Paris: Editions de Minuit; 1979.

51. Juan S. Sociologie de genre de vie. Paris: PUF; 1991.

52. Cathelat B. Publicité et société. Paris: Petit bibliothèque Payot; 2001.

53. Klatzmann J. L'agriculture française. Paris: Seuil; 1978

54. Grignon C, Grignon Ch. Styles d'alimentation et goûts populaires. Revue française de sociologie 1980; 21:531-69.

55. Bages R, Rieu A. Spécificité du mode d'approvisionnement alimentaire des agriculteurs. Ethnologie française 1988; 18:358-65.

56. Larrère $R$, de la Soudière M. Cueillir la montagne. Lyon: La Manufacture; 1985.

57. Lambert JL. Quelques déterminants socioculturels des consommations de viandes en Europe. La "vache folle" va-te-elle renforcé la tendance a la sarcophagie et au néo-végétarisme? Rev Droit Rurale 1997; 252:240-3.

58. Herpin N. Le repas comme institution, compte rendu d'une enquête exploratoire. Revue Française de Sociologie 1988; 26:503-21. 
59. Becker GS. A theory of the allocation of time. Economic J 1965; 75:493-517.

60. Déchaux J-H. Les trois composantes de l'économie cachée de la parenté: l'exemple français. Recherches Sociologiques 1994; 25(3).

61. Poulain J-P. Les racines du bien manger en Languedoc. In: Clavel J. Vin et cuisine de terroir en Languedoc. Toulouse: Privat; 1988.

62. Lambert JL. A table ! La cuisine du statisticien. In: La cité des chiffres. Paris: Autrement, Sciences en société; 1992. v.5:77-85.
63. Grignon C. Les conditions de vie des étudiants. Paris: PUF; 2000.

64. Desjeux D. Les échelles d'observation de la consommation. In: Comprendre le consommateur. Paris: Éditions Sciences Humaines; 1998.

65. Corbeau J-P. Rituels alimentaires et mutations sociales. In: Cahiers internationaux de sociologie. Cll, Paris: PUF; 1992. v.42.

66. Rivière C. Les rites profanes. Paris: PUF; 1995.

Recebido para publicação em 29 de setembro de 2003. 
386 | J-P. POULAIN \& R.P.C. PROENÇA

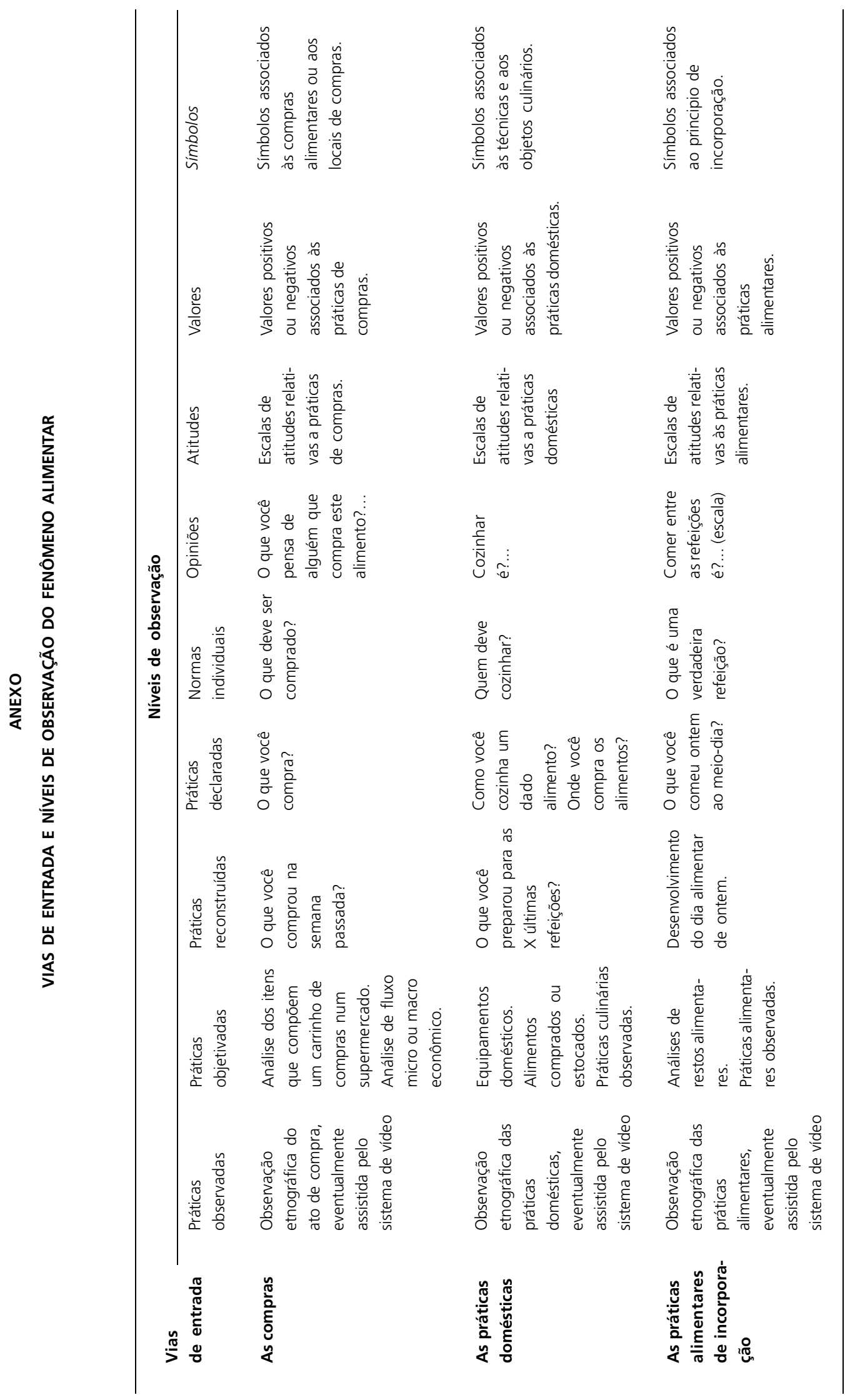

